\title{
Intervenciones y la geopolítica de lo imperial ${ }^{*}$
}

\author{
David SLATER \\ Department of Geography \\ Loughborough University (Reino Unido) \\ D.Slater@lboro.ac.uk
}

Recibido: 06-03-2014

Aceptado: 17-09-2014

\section{RESUMEN}

En este artículo trataré algunos de los elementos relacionados con el fenómeno general de lo que se podría llamar "intervencionismo geopolítico occidental" desde un punto de vista que enfatiza lo unilateral sobre lo multilateral. El argumento principal es que no es posible entender las dinámicas del intervencionismo independientemente de la geopolítica del poder imperial que se alimenta de una invasividad profundamente enraizada. Tras aclarar la diferencia entre imperialismo e imperialidad, se sugiere que para desarrollar una comprensión efectiva de lo imperial, nuestro análisis tendrá que: a) establecer una conexión tanto con la racialidad como con la sexualidad; b) examinar el vínculo entre lo imperial hacia dentro (at home) y lo imperial en el exterior (abroad), y c) considerar, aunque sea de forma breve, la relevancia de las relaciones centro-periferia. Todas estas conexiones reciben el nombre de "nexo imperial". Como conclusión subrayaremos que la geopolítica de lo imperial puede ser entendida como un nodo analítico de gran potencial creativo que, por lo tanto, puede aportar nuevas perspectivas dentro de un campo enormemente fértil y diverso.

Palabras clave: intervencionismo geopolítico; poder imperial; imperialidad; nexo imperial; soberanía.

\section{Interventions and the Geopolitics of the Imperial}

\begin{abstract}
In this paper I want to examine certain elements relating to the general phenomenon of what I shall call Western geopolitical interventionism. It is also important to bear in mind that an emphasis will be given to unilateral rather than multilateral. It is argued that we cannot fully understand the dynamics of interventionism in isolation from the geopolitics of imperial power which is propelled forward by a deeply-rooted invasiveness. After distinguishing imperialism from imperiality, it is suggested that if we are going to develop an effective understanding of the imperial, it will be beneficial to our analysis if we: a) make a connection with both raciality and sexuality; b) examine the linkage between the imperial at home and the imperial abroad, and c) consider, no matter, how briefly, the relevance of centre-periphery relations; I shall call these connections the imperial nexus. I conclude by stressing the point that the geopolitics of the imperial is most appropriately looked at as a potentially creative analytical node that can generate many new insights across a fertile and diversified terrain.
\end{abstract}

Key words: geopolitical interventionism; imperial power; imperiality; imperial nexus; sovereignty.

\footnotetext{
* Al autor le gustaría agradecer los comentarios de dos evaluadores anónimos, así como el apoyo efectivo del profesor Heriberto Cairo.
} 


\section{Intervenções e a geopolítica do imperial}

\section{RESUMO}

Neste artigo tratarei alguns dos elementos relacionados com o fenómeno geral do que se poderia chamar "intervencionismo geopolítico ocidental" desde um ponto de vista que enfatiza o unilateral sobre o multilateral. O argumento principal é que não é possível entender as dinâmicas do intervencionismo independentemente da geopolítica do poder imperial que se alimenta de uma invasividade profundamente enraizada. Depois de aclarar a diferença entre imperialismo e imperialidade, sugere-se que para desenvolver um entendimento efetivo do imperial, nossa análise terá que: a) estabelecer uma conexão tanto com a racialidade como com a sexualidade; b) examinar o vínculo entre o imperial para dentro (at home) e o imperial no exterior (abroad), e c) considerar, ainda que seja de forma breve, a relevância das relações centro-periferia. Todas estas conexões recebem o nome de "nexo imperial". Como conclusão sublinharemos que a geopolítica do imperial pode ser entendida como um nó analítico de grande potencial criativo que, portanto, pode contribuir novas perspectivas dentro de um campo enormemente fértil e diverso.

Palavras-chave: intervencionismo geopolítico; poder imperial; imperialidade; nexo imperial; soberania.

\section{REFERENCIA NORMALIZADA}

Slater, David (2014) "Intervenciones y la geopolítica de lo imperial". Geopolítica(s). Revista de estudios sobre espacio y poder, vol. 5, núm. 1, 35-62.

SUMARIO: Introducción. 1. Situando las intervenciones geopolíticas. 2. La soberanía en la sombra del poder imperial. 3. Explorando el nexo imperial. 4. Reencuadramiento de la geopolítica de lo imperial: algunos comentarios finales. Bibliografía.

\section{Introducción}

El telón de fondo de las intervenciones recientes por parte de Occidente en países como Afganistán, Iraq, Libia y Mali indica que claramente han vuelto a entrar en la agenda de la política global la cuestión general de la soberanía geopolítica y la reafirmación del llamado "imperialismo liberal" ${ }^{1}$. En este artículo consideraré ciertos elementos relacionados con el fenómeno general de lo que he de llamar "intervencionismo geopolítico occidental", con especial atención a su forma unilateral frente a la multilateral. Consideraré este tipo de intervención en relación a la manera en que pensamos sobre la democracia y la política de autodeterminación. A continuación, argumentaré que no es posible entender completamente la dinámica

\footnotetext{
${ }^{1}$ Dos textos complementarios que tratan sobre "imperialismo liberal" son Mehta (1999) y Pitts (2005). Se puede encontrar una discusión bien razonada sobre las relaciones entre liberalismo, imperio y derechos humanos en Dahbour (2007). Finalmente, véase Parekh (1997).
} 
del intervencionismo sin tener en cuenta la geopolítica del poder imperial impulsada por un fenómeno de invasividad fuertemente arraigado.

En potencia, nos encontramos ante una serie de vínculos entre el expansionismo, la intervención y la invasividad. El expansionismo es un rasgo característico de toda la política imperial, pero yo diría que aunque es una condición necesaria, no es una condición suficiente. Lo que resulta crucial es entender cuáles son las fuerzas que guían la voluntad de expandirse, así como las percepciones asociadas a este fenómeno por parte de las sociedades en las que el poder imperial se despliega. De alguna manera, el término "intervención" no capta en su totalidad la realidad de la penetración, puesto que al primero subyace un sentido de interposición entre dos entidades, que tiene una connotación bastante neutral. En las intervenciones que se mencionan en este artículo, los Estados Unidos no están presentes de una forma pasiva; sino de forma activa, disruptiva e invasiva. En la historia del imperialismo occidental, el poder invasor no se interpone de una forma pacífica, sino que despliega toda clase de formas de poder para alcanzar sus objetivos. Esta es la razón por la cual las intervenciones invasivas son una parte fundamental en la manera en que conceptualizamos el poder imperial —nos incitan a pensar de una forma más efectiva sobre lo imperial en la política mundial contemporánea-.

Teniendo presentes estas ideas, las dos primeras secciones del artículo versarán sobre la invasividad de las intervenciones geopolíticas y la fragilidad de la soberanía popular bajo la sombra del poder estadounidense. Considero que hay cinco conceptos que es útil considerar al explorar el significado de las intervenciones geopolíticas: a) deseo, b) voluntad política, c) capacidades, d) justificación, y e) resistencia. Dentro de esta primera sección del artículo también se intenta caracterizar la especificidad de los Estados Unidos como poder imperial postcolonial.

En la siguiente sección, dedicaré cierta atención a lo que he llamado "nexo imperial". Resulta necesario distinguir entre imperialismo e imperialidad; esta última se refiere al derecho, privilegio o sentimiento de ser imperial, o de defender las ideas del imperio. Sugiero que sería beneficioso para el análisis tener en cuenta las siguientes cuestiones: a) establecer un vínculo entre racialidad y sexualidad, b) examinar la conexión entre lo imperial "hacia dentro" (at home) y lo imperial en "el exterior" (abroad), y c) examinar, aunque de forma muy breve, el alcance de las relaciones centro-periferia. A todas estas conexiones las denomino "nexo imperial".

Mi atención analítica recaerá sobre la relación entre los Estados Unidos como poder imperial clave del mundo, y las sociedades del Sur Global, y especialmente del Sur Latino, lo que tradicionalmente se ha llamado América Latina. Este análisis se centra en las relaciones EE UU - América Latina. En este sentido, no quiero dar a entender que estas relaciones pueden siempre ser extrapoladas a los términos de Primer/Tercer Mundo. Simplemente son ilustrativas y sintomáticas de ese tipo de relaciones pero no agotan el terreno de las mismas. Concluiré poniendo de relieve que resulta apropiado acercarse a la idea de la geopolítica de lo imperial como un nodo analítico potencialmente creativo que puede generar muchas y nuevas percep- 
ciones de un terreno fértil y diversificado. De la misma manera, este punto nodal puede ayudarnos a empezar a repensar el conocimiento acumulado en torno al imperialismo en un contexto global (ver, por ejemplo, Mignolo, 2005). En este contexto, sugiero que es importante despegarse de un enfoque estrictamente economicista y desarrollar una perspectiva más multidimensional que abra espacio para nuevas ideas y líneas de investigación innovadoras.

\section{Situando las intervenciones geopolíticas}

Podemos entender la geopolítica del intervencionismo occidental como un ejemplo de la longevidad de una lógica invasiva o imperial que oficialmente incorpora un discurso de democracia y progreso, a través del cual y frecuentemente se retratan las intervenciones occidentales como parte de un proyecto a largo plazo de democratización del planeta; además de enmarcarse dentro de la difusión generalizada de los principios fundadores de la civilización occidental. Sin embargo, contrariamente a esta perspectiva de arriba abajo y con poca carga crítica, puede decirse que Occidente y, más concretamente, los Estados Unidos, han sido responsables tanto de la terminación de gobiernos democráticos en el Sur Global, y del respaldo a regímenes militares pro occidentales que, especialmente durante el periodo de la Guerra Fría, establecieron diversas formas de tiranía.

Irán en 1953, Guatemala en 1954, Brasil en 1964, Chile en 1973, Uruguay en 1973, Granada en 1983 y Nicaragua durante los años 1980 -aunque en este caso no se produjera una toma del poder por parte de los militares-, integran la lista de las intervenciones anglo-americanas para acabar con gobiernos democráticos ${ }^{2}$. Por su parte, dentro del apoyo otorgado a regímenes militares, se puede mencionar el caso de Argentina en 1976, Brasil en 1964, Chile en 1973 y Uruguay en 1973 -la lista aumentaría de forma considerable si incluyéramos ejemplos africanos y asiáticos-. Además, hemos de recordar que, como es evidente, Occidente continúa apoyando regímenes no democráticos en Oriente Medio (como ocurre con Bahréin, durante un largo periodo de tiempo con Egipto y Arabia Saudí; países que, por otra parte, cuentan con un historial de derechos humanos abominable).

Lo que hemos de subrayar aquí es que esas sociedades metropolitanas, en particular los Estados Unidos y el Reino Unido, que han proyectado una perspectiva panglosiana de su lugar en el mundo, cuentan con historias de penetración imperial en las sociedades del Sur Global, y que esas penetraciones reflejan una relación

\footnotetext{
${ }^{2}$ Para los casos de Irán y Guatemala ver, por ejemplo, Gaddis (2005: 162-171). Además, para un excelente repaso de la situación en los países del Cono Sur durante los años 1970 ver, por ejemplo, Corradi, Fagen y Garretón (1992).
} 
asimétrica entre las sociedades imperiales y las imperializadas que no debe ser olvidada. La manera en que estos acontecimientos son recordados variará notablemente entre el Norte y el Sur, y constituirá una parte significativa de la distinta naturaleza de, por un lado, el inconsciente político de las sociedades euronorteamericanas y, por otro lado, el de las sociedades periféricas no occidentales. Podemos pensar, en ese sentido, que acontecimientos como el derrocamiento de un gobierno democrático quedará clavado en la memoria de un pueblo del Tercer Mundo, mientras que en un país metropolitano, quedará poco o ningún recuerdo de, por ejemplo, el golpe de Estado militar que tuvo lugar en un país lejano. Es en este contexto al que se refiere Jameson (1992) con la distinción entre el Primer y el Tercer Mundo por la que, mientras que el primero tiene tanto el poder como la propensión a olvidar la historia geopolítica de las regiones del Tercer Mundo - a pesar de que esto está cambiando con las cuestiones de seguridad-, éste posee un espacio de maniobra más reducido y muestra una mayor dependencia del primero.

Cuando repasamos listas de injusticias en el mundo es poco frecuente encontrar alguna de las intervenciones geopolíticas mencionadas arriba; éstas tienden a permanecer invisibilizadas. Por ejemplo, en un artículo breve sobre la naturaleza y la variabilidad de la justicia internacional, Sen (2009: 26), dirigiéndose a una audiencia global, hace un listado de los siguientes tipos de injusticia: esclavitud, sumisión de las mujeres, explotación extrema del trabajo vulnerable, falta de atención médica de la mayor parte de la población del mundo actual, práctica continuada de la tortura y tolerancia silenciosa del hambre crónico. Que no quepa duda, todas estas son fuentes relevantes de injusticia, y ninguna de ellas es nueva ${ }^{3}$.

A pesar de que las anteriores son todas fuentes de injusticia muy relevantes, seguramente la violación repetida de la soberanía popular en el Sur Global necesita ser incluida en esta lista. De hecho, podría decirse que tales violaciones de la legalidad internacional y la negación de los derechos de los pueblos constituyen una forma cardinal o fundacional de injusticia internacional.

En ocasiones el alcance del intervencionismo es legitimado a través de la afirmación de que Occidente está expandiendo la democracia a un país que lo necesita, por ejemplo, Iraq o Afganistán. ¿Pero cómo se puede justificar la imposición de una forma de sociedad sobre otra sociedad? Judith Butler lo plantea de forma precisa: "¿qué quiere decir democracia si no se basa en la decisión popular y el gobierno de la mayoría $[. .$.$] puede el poder «llevar» o «instalar» la democracia en un pueblo$ sobre el que no tiene jurisdicción?" (2010: 36-37).

\footnotetext{
${ }^{3}$ En este sentido puede decirse que, poco después de la Segunda Guerra Mundial, el Secretario de Agricultura de los Estados Unidos, en una alocución frente a una comisión del Congreso señaló que "algunas personas van a tener que padecer hambre" (Berlan, 1952: 9).
} 
Es más, como señala Butler, aquellos que matan en nombre de la democracia o la seguridad, o aquellos que hacen incursiones en los territorios soberanos de otros en el nombre de la expansión de la democracia o los derechos humanos frecuentemente lo hacen como si estuvieran ejecutando una especie de "responsabilidad global". ¿Hasta qué punto es justificable esta supuesta responsabilidad? Es probablemente muy poco justificable dado que está insertada en la razón imperial o lo que Gill (2012) ha llamado recientemente "el sentido común imperial". Necesitamos repensar y reimaginar los significados de la responsabilidad global de forma que la geopolítica de la imposición y la apropiación imperial del concepto de responsabilidad puedan ser cuestionados y trascendidos.

Cuando examinamos la geopolítica del intervencionismo desde una perspectiva amplia, resulta claro que la justificación o legitimación de la invasividad occidental (por ejemplo, la exportación del modelo estadounidense de democracia basada en el mercado) está íntimamente ligada al deseo de intervenir; una idea de intervención que abarca otras dimensiones más allá de las tradicionales: extracción de materias primas, recursos y mano de obra barata. Estos son factores importantes que no pueden ser ignorados, pero el deseo de intervenir aglutina las presiones procedentes de lo geopolítico, lo cultural, lo militar, lo psicológico y lo económico.

Por encima de todo, yo diría que la naturaleza multidimensional del deseo requiere, dentro de una sociedad imperial emergente, la articulación y justificación continua de la expansión y la intervención; o, como lo formuló hace unos años el historiador marxista Kiernan "en primer lugar, los imperios han de contar con un molde de ideas o reflejos condicionados hacia los que fluir..." (1974: 100). En otras palabras, más allá de la repetición exclusiva de explicaciones socioeconómicas bien establecidas acerca del impulso expansivo del imperialismo, puede que sea más beneficioso un análisis de la formación de la razón imperial o del sentido común dentro de ciertas sociedades - algo claramente visible en Estados Unidos en el siglo XIX- De ahí que la preocupación por el deseo pueda llevarnos a emprender una discusión sobre la imperialidad - una perspectiva que descansa sobre el sentido de un privilegio y supremacía occidentales, que está fuertemente asentado en la sociedad occidental (volveré sobre este punto más tarde)—.

Aunque el deseo es fundamental, no es suficiente. Para que el deseo sea efectivo, ha de ser canalizado, y aquí es donde la voluntad política se hace necesaria. Es dentro del espacio político del Estado donde las diversas compulsiones y perspectivas societales se mediatizan y cristalizan en una estrategia específica. En el caso de la política exterior, la producción de una serie de doctrinas (por ejemplo, la Doctrina Truman, o la Doctrina Reagan) fueron el resultado del trabajo de intelectuales situados en el campo del poder gubernamental y se podría argumentar que cualquier teoría del imperialismo debe incluir una consideración acerca del papel que juegan los intelectuales de Estado en la formulación de una estrategia global. El Proyecto para un Nuevo Siglo Americano (Project for a New American Century) es un ejemplo de este punto particular. 
Asimismo, es igualmente importante subrayar la importancia de la capacidad. En otras palabras, si aceptamos la idea del desarrollo de una voluntad política imperial en el campo del poder estatal o gubernamental, se sigue que tal voluntad no será efectiva si no ha habido un desarrollo de la capacidad militar para llevar a cabo o implementar los puntos clave de esa voluntad política dada. Por ejemplo, los británicos tomaron las Malvinas en 1833, diez años después de la promulgación de la Doctrina Monroe, pero los Estados Unidos no disponían de la capacidad naval para enfrentarse a los británicos. Sin embargo, a finales del siglo XIX la situación era diferente puesto que los Estados Unidos tenían por entonces una flota poderosa. Así, en una disputa fronteriza entre Venezuela y la Guyana británica, Estados Unidos fue capaz de ganar la batalla y favorecer la posición de Venezuela, sobre lo que el Secretario de Estado Richard Olney afirmó de forma bastante categórica que Estados Unidos era prácticamente soberano "en este continente" (ver R. Olney, 1895: 64-67, cit. en Holden y Zolov, 2000).

Deseo, voluntad política y capacidades requieren una justificación. Esta podría ser la noción de que Occidente está difundiendo y exportando una serie de modos de organización societal beneficiosos a través de, por ejemplo, la expansión de la "civilización", la "democracia", y la "libertad". Estos cuatro elementos (es decir, el deseo, la voluntad política, la capacidad y la justificación o legitimación) nos ofrecen un marco posible para entender el intervencionismo geopolítico, pero debemos añadir un quinto elemento, que es el papel jugado por la resistencia. En este sentido, encontramos una serie de ejemplos de diferentes partes del mundo donde el punto más importante sigue estando relacionado con la percepción sobre la sociedad invadida por parte del que interviene y que, naturalmente, estará influido por la historia de las relaciones entre los dos países. En términos generales, en el caso de América Latina, el desarrollo del nacionalismo desde principios del siglo XX habría de ser visto como una respuesta a la "diplomacia del cañón" y el tipo de política imperial expresado en el Corolario Roosevelt de 1904.

El nacionalismo creciente también fue una respuesta a la necesidad de encontrar una identidad auténtica, que se expandió por todo el Sur Latino durante lo que se llamó "El Siglo Americano". En consecuencia, Washington modificó su aproximación a las intervenciones e introdujo a principios de los años 1930 lo que Franklin D. Roosevelt llamó la política de "buena vecindad", para que de esa forma las cuestiones de ayuda y comercio recibieran prioridad dentro del contexto general de relaciones interamericanas. Por lo tanto, como ejemplo, cuando la agitación política emergió en la Cuba de los años 1930, la administración estadounidense prefirió 
subrayar la relevancia del diálogo y la búsqueda del consenso antes que empuñar la primera arma para la guerra ${ }^{4}$.

Tal y como demuestran mis ejemplos, se puede argumentar que la lógica invasiva occidental ha sido un rasgo constante en las relaciones internacionales, dentro de las cuales las asimetrías del poder geopolítico están ancladas en la historia del encuentro colonial/imperial. Asimismo, resulta útil recordar que en Occidente la realidad de esta lógica invasiva ha tenido una presencia muy reducida en los estudios de globalización, modernidad y democracia. Además, cuando se examina este tema, resulta necesario indicar que el intervencionismo estadounidense posee una historia más larga de la que normalmente se asume. No se trata solo de un fenómeno adyacente al comienzo de la Guerra Fría y la rivalidad entre las dos superpotencias. Así, por ejemplo, en la historia de los Estados Unidos, las incursiones geopolíticas pueden llevarnos mucho antes de la Revolución bolchevique. Por ejemplo, en el periodo desde 1798 a 1895, los Estados Unidos realizaron 103 intervenciones en una serie de países - los ejemplos varían desde Nicaragua a China, Argentina y Japón o Hawái y el África occidental portuguesa (ver Zinn, 1996: 290291)-. Éstas fueron intervenciones militares rudimentarias que sucedieron antes de la aparición del peligro percibido de la Revolución de 1917 y el nacimiento del Estado comunista.

Tras estas incursiones y penetraciones, que se intensificaron a lo largo del siglo $\mathrm{XX}$, uno se encuentra con una imagen de los Estados Unidos como de "soberano global" que se arroga a sí mismo el poder de actuar por encima de la ley, cuandoquiera que le parece necesario. El bloqueo continuado de Cuba desde principios de los años 1960; el rechazo a la jurisdicción de la Corte Internacional sobre su ataque a Nicaragua a mediados de los años 1980; la más reciente invasión ilegal de Iraq; el uso ilegal extendido de drones por parte del Presidente Obama para llevar a cabo "asesinatos selectivos" en Afganistán y Pakistán; y el uso continuado de la tortura en, por ejemplo, la Bahía de Guantánamo —-todos estos ejemplos otorgan credibilidad a la idea de que, en última instancia, los Estados Unidos son el verdadero "Estado canalla" 5 - ¿Cuáles son entonces las consecuencias del despliegue continuado de este tipo de poder, poder imperial, en las sociedades del Sur Global, y en la manera en que conceptualizamos su política? Llegados a este punto, resultaría ciertamente insensato ignorar la influencia de la única superpotencia que queda en el mundo, un Estado que ha sido descrito como un "poder supremo" (Brzezinski, 2004: xii).

\footnotetext{
${ }^{4}$ No quiero hacer demasiado hincapié sobre este punto, puesto que obviamente los Estados Unidos siguieron siendo un poder imperial, pero en los años 1930 identificamos una cierta flexibilidad y, en general, una política exterior menos autoritaria.

${ }^{5}$ Para una revisión actualizada de la idea de Estados Unidos como "Estado canalla" ver Chomsky y Vltchek (2013).
} 


\section{La soberanía en la sombra del poder imperial}

Cuando dirigimos nuestra atención a la escala del Estado-nación, una especie de pivote geopolítico, es importante considerar el concepto de la autodeterminación popular. Una definición - que nos lleva por un camino fértil- reza que ningún gobernante de un Estado tiene el derecho a interferir en el gobierno de otro, "y el gobierno del dirigente de un Estado no está sujeto a la decisión del dirigente de ningún otro Estado"; además, se sugiere que "el argumento moral de mayor peso para la autodeterminación es que la independencia política es necesaria para la eliminación de la injusticia social y el desarrollo de instituciones justas" (Beitz, 1979: 75). Así, el despliegue de poder imperial claramente violaría este tipo de relaciones ya que el nexo imperial implica la subordinación directa o indirecta de otros Estados. Expresado en términos parecidos, diríamos que la dominación imperial supone la subordinación de la soberanía de otro Estado a través del ejercicio de un poder jerárquico en formas diversas, que incluyen la militar, política, económica y cultural. Por ejemplo, los Estados Unidos han actuado como un poder imperial clásico en la periferia postcolonial, y aunque no se anexionara territorios - con excepción de las Filipinas- la fuerza fue usada constantemente para diezmar las transformaciones sociales revolucionarias, ya fueran nacionalistas o socialistas/comunistas, y para contener los desafíos que habrían desencadenado en una mayor autonomía postcolonial (me vienen a la mente los ejemplos de Cuba, Nicaragua, Vietnam e Indonesia) ${ }^{6}$.

Además, tal y como nos recuerda Golub (2010: 14-15), "la amplia esfera informal del Imperio americano ha descansado siempre sobre la seguridad del planeta establecida durante la Segunda Guerra Mundial y cuyos puntos adelantados, el archipiélago de tierra — bases y plataformas militares flotantes diseminadas por el mundo-, constituyen las fronteras móviles de la soberanía de los Estados Unidos y deberían ser entendidas como nodos territorializados del imperio" (énfasis añadido) ${ }^{7}$. Esta situación no ha cambiado durante la Presidencia Obama, que en América Latina dejó ver sus intenciones a través de su actitud tolerante con el golpe militar de 2009 en Honduras, y con la orden de expansión de bases norteamericanas en

\footnotetext{
${ }^{6}$ Anderson (2013) hace una distinción útil entre fuerza y violencia encubierta. Con respecto a la última, señala inter alia el pago de público en Irán, los subsidios a los señores de la guerra en Afganistán o a los disidentes polacos. Además, señala que Estados Unidos ha desarrollado una amplia variedad de métodos para hacer cumplir su voluntad, incluyendo bombardeos aéreos, sanciones económicas, ataques con misiles, bloqueos navales, tortura y asesinatos. Anderson además señala que "el amplio consentimiento con que cuenta el poder imperial americano en el primer mundo no existía en el tercer mundo" (2013: 55-56).

${ }^{7}$ Desde una perspectiva similar pero distinta, Stoler (2006) desarrolla un argumento relacionado con lo que llama "grados de soberanía imperial" que conecta con el texto de Golub y nos proporciona un vínculo con el trabajo de Johnson (2004) sobre las bases del imperio americano.
} 
Colombia - con el claro objetivo de ejercer más presión sobre los países vecinos de Venezuela, Ecuador y Bolivia-.

Tanto la idea de autodeterminación como la de autogobierno y soberanía popular expresan un sentido profundo de independencia y autonomía y, por lo tanto, entran en conflicto con la omnipresencia del poder imperial estadounidense. Y, sin embargo, existe un factor que hasta cierto punto ensombrece la dicotomía entre imperialidad del poder y las expresiones de autonomía postcolonial. Así, cuando se examinan las especificidades de los Estados Unidos en el mundo, resulta demasiado rígido pensar que los Estados Unidos son incansablemente contrarios a la autodeterminación o se oponen completamente a las realidades de la independencia de las naciones del mundo (ver, por ejemplo, Simpson, 2012). Expresado de otra manera, a pesar de que Estados Unidos se ha desarrollado como un poder imperial que se ha enfrentado a la articulación de otras posiciones independientes (por ejemplo, en relación con la difusión de la "marea rosa" en América Latina), en su faceta de Estado originalmente postcolonial, la idea de autodeterminación se ha presentado como una idea específicamente americana. Esta yuxtaposición contradictoria o choque entre identidades en conflicto emergió como resultado de la derrota del colonialismo británico en el continente norteamericano que, durante el siglo XIX, permitió la expansión de los Estados Unidos y el establecimiento de las bases iniciales de un poder imperial.

Lo que esto significa es que los Estados Unidos es la única nación occidental que puede ser considerada como un poder imperial postcolonial. Al declarar su independencia de Gran Bretaña, los Estados Unidos se convirtieron en una sociedad postcolonial. Esta ascendencia ha ejercido una gran influencia sobre la formulación de su política exterior y la representación general de sí mismos tanto hacia dentro como hacia fuera. De ahí que cuando los Estados Unidos han intervenido en otro país, o han amenazado con intervenir, se ha llevado a cabo una separación discursiva entre los gobernantes y los gobernados o entre el gobierno y el pueblo. En otras palabras, en ocasiones Estados Unidos ha adoptado un manto de protección sobre la población de otro país para defenderlos de su propio gobierno, como en el caso de Cuba con el Acta Helms-Burton de 1996 y con la invasión de Granada en 1983. Lo que quiero decir aquí es que Estados Unidos, al actuar implícitamente como el "soberano global", ha construido una trayectoria de tutela sobre sociedades periféricas y más vulnerables.

Más recientemente, en un discurso de 2011 ampliamente difundido, el Presidente Obama decía a los americanos que "debemos recordar que lo que distingue a América no es únicamente su poder, son los principios sobre los cuales se fundó nuestra Unión [...] No apoyamos el imperio, sino la autodeterminación [...] es por ello que apostamos por las aspiraciones democráticas que están recorriendo el mundo árabe" (énfasis añadido) (citado en Simpson, 2012: 693).

En este fragmento Obama establece una conexión con la larga tradición estadounidense de representarse a sí mismos como los guardianes de la virtud democrática 
y custodios de la autodeterminación de los pueblos del mundo. En este texto también se establece una conexión con un discurso de excepcionalismo y con la afirmación de que el destino especial de América le permite perseguir políticas destinadas a la democratización de dictaduras porque su propia existencia es merecedora de medidas especiales - un tipo de razonamiento no permitido a otras naciones-. Se da por hecho aquí también una presunción de inocencia o, en palabras de Barber, "el mito de la inocencia protege a América [...] de las pesadas cargas de la responsabilidad histórica para la guerra o la anarquía o la injusticia o la conquista" (2004: 81). En un sentido parecido, Atwood escribe que "la guerra es el modo de vida americano" y "el proyecto americano empezó con violencia" [...] "El mito de la inocencia está profundamente anclado en la historia geopolítica estadounidense, acompañado de una representación frecuentemente negativa de otras sociedades; y se ha de subrayar que el mito de la inocencia y la virtud sigue vigente en el periodo contemporáneo" (2010: 231)8.

La Estrategia de Seguridad Nacional de 2010 constituye un ejemplo reciente de proyección de una imagen inocente y benevolente de la historia de los Estados Unidos. El siguiente párrafo capta la esencia de esta proyección de magnanimidad y virtud:

El ejemplo de América es un componente crucial de nuestra fundación. Los derechos humanos que América ha defendido desde nuestra fundación han hecho posible nuestro liderazgo, han sido una fuente de inspiración para los pueblos de todo el mundo, y han establecido un claro contraste entre los Estados Unidos y nuestros aliados democráticos, y aquellas naciones e individuos que niegan o reprimen los derechos humanos. Nuestros esfuerzos por vivir nuestros propios valores y apoyar los principios de democracia en nuestra propia sociedad, subrayar nuestro apoyo a las aspiraciones de los oprimidos del mundo que saben que pueden contar con el liderazgo de América basado en la justicia y la esperanza (The White House, 2010: 10).

A pesar de que esta perspectiva oficial está ampliamente presente en interpretaciones de la política exterior de Estados Unidos, se identifican algunas rupturas expresadas por ciertos intelectuales de la defensa o líderes gubernamentales cuyas visiones van a contracorriente del relato dominante. Un ejemplo es especialmente pertinente: en su libro de 1995 sobre la guerra de Vietnam, In Retrospect, el exsecretario de Defensa Robert McNamara identificó una serie de razones por las cuales

\footnotetext{
${ }^{8}$ En un texto clásico sobre diplomacia americana, Williams (1972) sugiere que en el ámbito de las ideas y los ideales, la política americana se guía por tres concepciones: a) el impulso humanitario por ayudar a otros pueblos; b) la aplicación del principio de autodeterminación a nivel internacional; y c) la idea de que otros pueblos no pueden realmente resolver sus problemas y mejorar sus estándares de vida a menos que procedan de la misma manera que los Estados Unidos, por lo tanto, apoyando muchas veces de forma poco crítica la americanización (Williams, 1972: 13).
} 
se produjo el desastre de Vietnam. Los siguientes puntos son un resumen del texto de McNamara, que en total señala once errores y del que aquí solo subrayaré cinco: 1) Exageramos el peligro que representaban las acciones vietnamitas para los Estados Unidos y formamos un juicio equivocado sobre sus intenciones geopolíticas; 2) visualizamos al pueblo y a los líderes de Vietnam del Sur de acuerdo con nuestra propia experiencia; 3 ) infravaloramos el poder del nacionalismo como acicate para que los pueblos luchen y mueran por sus creencias y valores; 4) nuestro juicio tanto del amigo como del enemigo reflejó nuestra profunda ignorancia sobre la historia, cultura y política de las gentes en cuyo territorio estábamos involucrados (énfasis añadido); y, 5) no reconocimos que ni nuestro pueblo ni nuestros líderes son omniscientes y que, además, no disponemos del derecho divino a modelar cualquier nación a nuestra imagen y semejanza (McNamara, 1995: 321-323).

Estos puntos siguen siendo fundamentalmente relevantes, van al quid de la cuestión, revelan la profundidad de la falta de entendimiento, los juicios equivocados $\mathrm{y}$ prejuicios que plagaron el desarrollo de la guerra de Vietnam desde el lado norteamericano. A ello se añade que otras muchas sociedades no occidentales han sufrido una forma muy específica de ignorancia condescendiente desplegada por Occidente; los mismos prejuicios salieron a la luz en el periodo que precedió a la invasión de Iraq, el mismo tipo de prejuicios del que habló Said en el prefacio de su Orientalismo (Said, 2003).

\section{Explorando el nexo imperial}

Al poner en relación las cuestiones anteriormente tratadas sobre la soberanía y el poder imperial y el campo más amplio de la geopolítica, puede tener sentido referirse al argumento bien conocido de Laclau y Mouffe que, en su texto de 1985, Hegemonía y Estrategia Socialista, observan que se puede trazar una diferencia fundamental entre las sociedades industriales avanzadas y la periferia del mundo capitalista. En el mismo texto subrayan que "la proliferación de puntos antagonistas permite la multiplicación de las luchas democráticas, pero dada su diversidad, estas luchas no tienden a constituir un "pueblo», es decir, no tienden a construir la equivalencia entre uno y otro ni a dividir el espacio político en dos campos antagonistas". Por el contrario, "en países del Tercer Mundo, la explotación imperialista y el predominio de formas de dominación brutales y centralizadas tienden desde el principio a dotar a la lucha popular de un centro, un único enemigo claramente definido. Aquí la división del espacio político en dos campos está presente desde el comienzo, pero la diversidad de las luchas democráticas es más reducida" (Laclau y Mouffe, 1985).

Para llevar esta diferenciación un poco más allá podemos recordar otra de las cuestiones que señala Laclau en un artículo similar en torno a la democracia y el poder (2001). Aquí se sugiere que el proceso democrático acarrea una ambigüedad 
inherente. De ahí que, por un lado, la democracia pueda ser vista como el intento de organizar el espacio político alrededor de la universalidad de la comunidad en un intento por construir la unidad de un pueblo. Por otro lado, también se puede concebir la democracia como la extensión de una lógica de igualdad a esferas más amplias de las relaciones sociales (igualdad social y económica, igualdad racial, de género, etc.) de forma que en este sentido la democracia implica el respeto por las diferencias. Por lo tanto, la ambigüedad de la democracia puede ser formulada como una necesidad de unidad que solo puede ser pensada a través de la diversidad (Laclau, 2001: 4).

Pues bien, ¿cómo se relacionan estos distintos puntos con la cuestión de la democracia imperial? En el contexto de la política global, el intento de exportar y favorecer una versión de la democracia (la visión neoliberal) como un proyecto unificador por encima de las fronteras se da de bruces con la lógica de la diferencia, pero de una forma que está imbricada en el discurso nacionalista. De acuerdo con la formulación de Laclau (2001) y Mouffe (2000), así como otros autores que han avanzado en teorizaciones sobre la cuestión de la democracia como Lefort (1988) y Rancière (1995), hay una aceptación implícita de que estamos tratando aquí con comunidades políticas territorialmente intactas, lo cual puede ser un principio razonable si pensamos en Gran Bretaña, Francia o los Estados Unidos, pero que deviene mucho menos realista cuando se trata de una sociedad del Sur Global. En otras palabras, estamos ante un principio rector que señala que se puede desarrollar el campo conceptual de acuerdo con un contexto geopolítico donde la soberanía territorial del Estado-nación no encuentra desafíos. Sin embargo, teniendo en cuenta la presencia global de un poder (o poderes) imperial la autonomía de los diferentes experimentos democráticos puede estar sujeta a la subversión externa; se puede dar, como ha ocurrido históricamente y se ha señalado anteriormente en este artículo, otra lógica desestabilizadora que puede tener la capacidad de acabar con dos lógicas autóctonas en relación a la universalidad y la diferencia. En este sentido, la tensión interna entre la lógica de la unidad y la lógica de la diferencia puede quedar ensombrecida o ser desplazada por una lógica imperial de incursión e invasión; lo que significa que estamos tratando con tres lógicas, de las cuales una está basada en un factor externo.

El desafío al poder imperial suele ir acompañado al mismo tiempo de una tendencia hacia la ampliación de las demandas popular-democráticas. En el contexto de las relaciones EE UU - América Latina, la misión de universalización de una forma específica de democracia à la americana se topa con un amplio espectro de fuerzas políticas y partidos y movimientos sociales (ver, por ejemplo, GuardiolaRivera, 2010: 368-369, y Milne, 2012: 197-219). El sentimiento imperial y el peso de los procedimientos y estructuras imperiales pueden sostener la promoción de la democracia liberal dentro del territorio nacional, pero es activamente contestado en un continente cansado de ser retratado como un objeto pasivo. De hecho, es en América Latina donde uno puede encontrar nuevas aproximaciones a la democracia 
$\mathrm{y}$, desde una perspectiva gramsciana, una especie de optimismo de la voluntad, o lo que Guardiola-Rivera (2010) llama una "nueva política transformadora"9.

$\mathrm{Al}$ mismo tiempo es importante no caer en el romanticismo. Por ejemplo, la marea rosada no está exenta de disonancias y divisiones, y sucesos recientes como el golpe de 2009 en Honduras, y el intento de golpe en Ecuador pueden indicar que, al menos temporalmente, la "marea" ha de ser revisada. No obstante, merece la pena señalar que unos veinte años después de la desintegración de la Unión Soviética, la mayoría de las poblaciones de América Latina viven bajo gobiernos elegidos democráticamente y que de alguna manera se identifican a sí mismos como "socialistas", aunque esto se exprese en términos muy generales. Resulta sensato pensar que la marea ha sido democrática, pero tal y como señala acertadamente Beverley (2011: 11), los intentos de bloquearla como el intento de golpe fallido contra Chávez en 2002, o la movilización conservadora contra Evo Morales en la región boliviana de Santa Cruz de la Sierra, o la militarización del campo colombiano, son expresiones de una forma resucitada de política autoritaria.

Al mismo tiempo Laclau (2005: 230-231) subraya la idea de que la irrupción de nuevas demandas se da en sociedades que son todavía fuertemente capitalistas. Para Laclau el capitalismo puede ser definido como un complejo en que determinaciones económicas, políticas, militares, tecnológicas y de otro tipo están dotadas de su propia lógica, pero cada una determina el movimiento del todo; esto puede ser entendido como una nueva forma de capitalismo globalizado, en donde han emergido nuevos antagonismos, y donde se da una mayor proliferación de la diferencia. Al mismo tiempo podemos referirnos a una crítica temprana al capital que subrayaba la idea de que el capital es un forma de poder mayor, más creativa y destructiva que ninguna otra cosa en la historia de la humanidad y que su fuerza fundamentalmente antidemocrática continua coartando la expansión de la emancipación en todas las esferas de la vida social.

La emancipación puede adoptar varias expresiones, de las cuales un ejemplo claro es la lucha contra el poder imperial. Cuando nos planteamos preguntas acerca del desafío a la mentalidad imperial, para empezar es importante tener en cuenta que lo imperial no es un fenómeno que pertenezca exclusivamente al mundo de las relaciones internacionales; por el contrario, el presente imperial apunta al corazón de la sociedad occidental. Por ejemplo, Paul Gilroy (2005: 142) nos recuerda que los imperios no constituían solamente terminales lejanos para la actividad comercial,

\footnotetext{
${ }^{9}$ Conviene recordar que la izquierda latinoamericana cuenta con una historia vibrante plagada de muchos logros de gran calado político, incluyendo la Revolución cubana, el gobierno de Salvador Allende, la victoria sandinista, los gobiernos postneoliberales en Venezuela, Bolivia y Ecuador, la construcción de poder local y regional en lugares como Chiapas y los experimentos con presupuestos participativos, de los cuales los más importantes se desarrollaron en la ciudad de Porto Alegre. Una interesante panorámica de aspectos clave de la izquierda en América Latina se puede encontrar en Sader (2011).
} 
sino que en realidad se importaron las mentalidades imperiales al territorio nacional del país antes de la propia llegada de los inmigrantes. Esta transferencia ayudó a la generación de una subjetividad imperial en las sociedades occidentales que se ahondó a través del desarrollo del encuentro colonial e imperial. Es más, tal y como nos recuerda Kaplan (2002) para el caso de los Estados Unidos, hubo muchos ejemplos de íntima conexión entre la formación de la identidad nacional y la expansión imperial. Además, Kaplan señala correctamente que, mientras que por un lado la cultura imperial trata a la anarquía como una sombra amenazante que ha de ser controlada; por otro lado, el imperio puede igualmente inducir a la división y a la discordia. En los periodos post intervención ello conduce al fracaso y a nuevas formas de desestabilización, desorden y conflicto político, como ha sido el caso tanto de Afganistán como de $\operatorname{Iraq}^{10}$.

La intervención con el objetivo de acabar con la inestabilidad y garantizar la seguridad geopolítica se ha erigido como un elemento clave de la política exterior estadounidense desde comienzos del siglo XX. El Corolario Roosevelt, la Doctrina Truman, el pacto de Río y la Estrategia Nacional de Seguridad de 2002, 2006 y 2010 encarnan, inter alia, este principio.

Volviendo a la mitad del siglo XX y al comienzo de la geopolítica de la Guerra Fría, puede decirse que Estados Unidos se caracterizó por el establecimiento de un Estado de seguridad nacional y un proceso incipiente de militarización que incluyó una nueva política de subjetividad. La Guerra Fría no fue solo un fenómeno de la política mundial; estaba ligada al "temor rojo" y al Comité de Actividades Antiestadounidenses (House Un-American Activities Committee). Las actividades del senador republicano Joseph McCarthy se dirigían al corazón del temor rojo, siendo el macartismo el reflejo doméstico de la Guerra Fría donde las personas que eran críticas o cuestionaban su aproximación política eran estigmatizadas como traidores, conciliadores y desviados, así como sujetos a una discriminación constante. La Guerra Fría encarnó la contención y la intervención tanto dentro como fuera del país. Su retrato de "nosotros" y "ellos", o "amigos" y "enemigos", amenazas internas o externas, puso en relación cuestiones de seguridad, geopolítica, subjetividad y poder, de forma que el proceso de civilización y modernización del otro no occidental pudiera ser definido como una cuestión de seguridad y estabilidad que trascendía las fronteras nacionales.

\footnotetext{
${ }^{10}$ En el caso específico de Iraq, la ocupación ha generado nuevas formas de desorden que continúan atravesando el país. En un análisis oportuno de los crímenes del gobierno neoliberal en el Iraq ocupado, Whyte (2007) señala que una proporción desconocida de los beneficios del petróleo iraquí ha desaparecido en los bolsillos de contratistas y técnicos a través de sobornos, sobrecargo de costes, malversación de fondos, sustitución de productos, fraude en las licitaciones y reclamaciones falsas. A los al menos 12 millones de dólares desaparecidos se añade una ocupación en el terreno que provoca desunión política y que ha abierto el espacio a actividades terroristas llevadas a cabo por grupos afines a Al Qaeda. Para una reflexión general y provocadora de las relaciones entre el imperio y el caos, ver Joxe (2002).
} 
En un contexto más contemporáneo, caracterizado por la Guerra Contra el Terror que se desata desde, aproximadamente, el 11 de septiembre de 2001, identificamos una perspectiva más autoritaria frente a las esferas internacional y doméstica. En una democracia cada vez más privatizada y militarizada, Human Rights Watch ha documentado el incumplimiento constante de la ley en el tratamiento de prisioneros y detenidos en Afganistán, Guantánamo y Abu Ghraib. De acuerdo con Eisenstein (2007: 54), ahora se permiten la humillación, la degradación y los interrogatorios coercitivos, y el Comandante en Jefe de las Fuerzas Armadas no está sujeto al derecho internacional. Asimismo, se han creado puntos en el extranjero cuya situación no ha sido desvelada, situados en zonas prohibidas, en los que detener a sospechosos de terrorismo; un proceso calificado como de "rendición extraordinaria" (Scahill, 2013: 25-30). Además, la administración Obama ha ampliado el uso de drones - sistemas aéreos no pilotados ilegales-y en 2011 el ejército norteamericano llevó a cabo cientos de golpes en seis países, transformando la manera en que la democracia occidental, pero sobre todo estadounidense, participa en lo que se sigue llamando guerra. En un caso particular, Pakistán, Estados Unidos llevó a cabo más de 300 ataques con drones entre los años 2004 y 2011 (ver Singer, 2012: 6).

Junto a la práctica de controles policiales globales, la Estrategia de Defensa estadounidense de 2008 incluye el objetivo de trabajar con y en Estados afines para "ayudar a reducir las áreas no gobernadas del mundo y, de esta forma, negar refugio a los extremistas y otros grupos hostiles; al ayudar a otros a conducirse a sí mismos $\mathrm{y}$ sus regiones, haremos frente de forma colectiva a las amenazas al orden internacional en términos amplios" (énfasis añadido, Department of Defense, 2008: 9-10). En este sentido, se debe examinar críticamente la idea de colectividad, puesto que siempre se define el papel de los Estados Unidos como líder o custodio, o más recientemente, en el contexto de relaciones EE UU - América Latina, como un "mentor" (ver Kelly, 2013: 19).

La seguridad, la vigilancia y las labores de policía tanto dentro como fuera del territorio estadounidense se han convertido en elementos clave de una mentalidad cada vez más militarizada. Dentro del territorio nacional de Estados Unidos los ciudadanos están sometidos a una vigilancia más intensa a través de nuevos mecanismos como el Patriot Act, y al espionaje que acreditan las revelaciones recientes de la Agencia de Seguridad Nacional y que se extiende al resto del planeta. Además, no podemos pasar por alto el uso probado de la tortura, tal y como confirmó el grupo de once expertos que recibió el encargo de parte del grupo de trabajo Constitution Project, con sede en Washington DC, y que concluyó que "no cabe duda de que los Estados Unidos han estado involucrados en la práctica de la tortura" (Shane, 2013: 1 y 5).

Fuera del territorio americano las áreas del mundo llamadas sin gobierno (ungoverned), infragobernadas (undergoverned) o mal gobernadas (misgoverned) se han incorporado a la gestión del riesgo geoestratégico donde tal y como señala el consejero del Pentágono, Barnett (2004: 25), los Estados Unidos han de hacer cumplir la 
ley establecida para las relaciones internacionales y discriminar entre buenos y malos Estados. Es en este sentido donde encontramos diversos debates acerca de la supuesta existencia de Estados canalla o fallidos.

Para abrir esta sección del artículo me he referido a la noción de "nexo imperial". ¿Cuál es el significado real de este término? En primero lugar, el nexo imperial se refiere a la manera en que lo imperial conecta y se solapa con lo racial y lo sexual, de forma que para comprender de manera integral la naturaleza de la imperialidad necesitamos ponerlo en relación con una perspectiva que puede iluminar conceptos sobre racialidad y sexualidad. Pero antes de embarcarnos en esa travesía necesitamos tener una idea más clara de la diferencia entre imperialismo e imperialidad.

Expresado en términos generales, el imperialismo, y más concretamente el imperialismo estadounidense, puede ser definido como la matriz de estrategia, políticas, práctica e intervención que buscan establecer y reproducir las condiciones que posibilitan su poder global y, en particular, su deseo y capacidad de subordinar sociedades de la periferia postcolonial con el fin de socavar y subvertir su soberanía política. Siguiendo a Golub podemos añadir que, la pax americana se ha basado en múltiples jerarquías, de tal manera que en el norte de Europa, los Estados Unidos han favorecido el desarrollo económico y los Estados democrático-liberales, mientras que en el noreste asiático, con la excepción de Japón, coadyuvó al establecimiento y mantenimiento de "Estados semisoberanos y desarrollistas bajo su control" (2010: 15). En cambio, en la periferia postcolonial, se ha empleado constantemente la fuerza con el fin de limitar la posibilidad de transformaciones sociales revolucionarias y prevenir el desarrollo de un mayor grado de autonomía geopolítica. En este sentido, debemos hacer hincapié, como se ha mencionado en una nota al pie anterior, en que además del uso palpable de la fuerza, los Estados Unidos han hecho uso de otros muchos métodos soterrados de intervención violenta para imponer su voluntad ${ }^{11}$.

La estrategia imperial se desarrolla fundamentalmente dentro del espacio político del Estado. Recientemente el programa llamado Proyecto para un Nuevo Siglo Americano se ha construido como diseño para un siglo, o quizá para un periodo algo más extenso, destinado a ser fundamentalmente americano. Los intelectuales conservadores asociados al proyecto, como Richard Perle y Paul Wolfowitz, ejercieron una gran influencia en el diseño de la política exterior de la Administración Bush y nos ofrecen un ejemplo muy pertinente de la manera en que la estrategia imperial se construye dentro del espacio institucional del Estado.

\footnotetext{
${ }^{11}$ Es un hecho de la vida académica que mientras que la mayor parte de los autores convendrá, más o menos a regañadientes, que los Estados Unidos han utilizado la violencia para la consecución de sus objetivos en la mayor parte del mundo, existe una reticencia implícita a abordar la cuestión en términos de terrorismo de Estado. Un texto útil, pero poco citado, es el de Gareau (2004). También son útiles cualquiera de las contribuciones de Chomsky al tema, por ejemplo, Chomsky y Vltchek (2013).
} 
Frente al imperialismo, la imperialidad puede ser entendida como un término compuesto que evoca el derecho, privilegio y sentimiento del ser imperial, o la defensa de las ideas del Imperio en el que se justifica la invasividad geopolítica del poder de Occidente y, más concretamente, de los Estados Unidos. De ahí que sociedades como la estadounidense alberguen discursos imperiales cuya raíz y sedimento se encuentran en la historia de sus relaciones geopolíticas. Así, la estrategia activa de expansión imperial puede ser mantenida a nivel discursivo basándose en la interpelación directa a un sentido de privilegio imperial profundamente enraizado. De hecho, se puede dar un proceso mutuamente constitutivo por el cual una estrategia activa de imperialismo sea apoyada por una reserva de sentimiento imperial que a su vez se refuerza gracias a una estrategia imperial reforzada. Sin embargo, cuando en la sociedad ha habido una importante oposición a la guerra, como en el caso de Vietnam, la efectividad de la imperialidad se debilita. Mucho de ello depende de una guerra de ideas, o de una guerra sobre los significados geopolíticos que se caracterizan de forma significativa por las disputas sobre lo que permanece en la memoria y lo que está condenado al olvido (Mignolo, 2005).

Además, el nexo imperial conecta tanto el adentro (home) como el afuera (abroad) con significados raciales y sexuales. Dentro de los Estados Unidos, por ejemplo, en su análisis de la cultura imperial y la "paranoia masculina y blanca", Kennedy sugiere que la negación de la presencia imperial se ha visto eclipsada por el argumento de que los Estados Unidos son una nación imperial en donde las culturas y mitologías domésticas todavía se ven modeladas por los mecanismos globales de la construcción del imperio. Continúa argumentando que la dominación de los otros internacionales ha dependido de la domesticación del otro en el terreno doméstico, que "recientemente la emergencia pública de una paranoia específicamente masculina y blanca en los Estados Unidos revela los mecanismos del inconsciente imperial en la masculinidad blanca americana" (Kennedy, 1996: 89). Esta ira alimenta el reclutamiento militar que se promociona en parte a través de la invasión de todos los medios de entretenimiento y una fuerte apelación a la hipermasculinidad de los hombres jóvenes. Para Giroux (2004), no se pueden desvincular las actividades militares en el exterior de la militarización creciente de la sociedad en territorio nacional: se libran guerras contra las drogas, se criminalizan las políticas sociales, las tasas de encarcelamiento aumentan entre los pobres, de los cuales un 50 por ciento son afroamericanos, y las escuelas se asemejan cada vez más a las cárceles. Giroux observa que la novedad ahora es que la militarización que sigue al 11-S se ha naturalizado, afectando a las vidas, memorias y experiencias cotidianas de la gente a la vez que socava cualquier aproximación crítica y emancipatoria de la historia, la justicia y el significado de la democracia.

Volviendo al vínculo entre la imperialidad y la racialidad, como se ha mencionado anteriormente, merece la pena recordar algunas de las agudas observaciones sobre la raza y el imperialismo hechas por Hannah Arendt (1975) en su análisis de los orígenes del totalitarismo. Arendt mostró bastante exitosamente cómo el impe- 
rialismo necesitaba del racismo como única excusa para sus actos. Asimismo, argumentó que el racismo ha sido la poderosa ideología de las políticas imperialistas, y la exclusión que subyace en principio de la idea de humanidad (y que constituye la única idea reguladora del derecho internacional) es completamente inaceptable: "La raza es, políticamente hablando, no el principio de la humanidad sino su fin, no el origen de los pueblos sino su decadencia, no el nacimiento natural del hombre sino su muerte artificial" (Arendt, 1975: 157).

De manera bastante parecida, Foucault argumenta que el racismo estalló cuando el derecho a quitar la vida se convirtió en imperativo. Así, el racismo primero se desarrolló de la mano de la colonización o del "genocidio colonizador": resulta ser la "precondición indispensable que permite matar a alguien [...] una vez que el Estado despliega sus formas de biopoder, el racismo por sí mismo puede justificar el papel asesino del Estado" (2003: 254-258). Y de nuevo con un mayor énfasis Foucault señala que "de qué manera se puede justificar la necesidad de matar gente, de matar poblaciones y de matar civilizaciones", y la respuesta es "apelando al racismo" (2003: 254-258). Para Foucault el racismo abre la posibilidad de establecer una relación entre mi vida y la muerte del otro; "esto es una relación de tipo biológico" o, más concretamente, "el racismo justifica la función muerte en la economía del biopoder al apelar al principio de que la muerte de los otros hace a uno biológicamente más fuerte en tanto en cuanto uno es miembro de una raza o una población" (2003: 254-258). A esto añade, "el racismo está ligado a los mecanismos del Estado que está obligado a utilizar la raza, [...] para ejercer su poder soberano" (2003: 254-258).

Si hacemos una parada momentánea en el siglo XIX, nos daremos cuenta de que la construcción de los imperios fue coetánea a la explosión del racismo militante, de tal forma que un científico bien conocido, un tal Robert Knox, escribió que "la raza es todo: literatura, ciencia, arte, en un mundo que depende de ella" (citado en Lindqvist, 1998: 125). La irrupción de un racismo beligerante tuvo muchos resultados concretos sobre el terreno. Por ejemplo, en Estados Unidos, alrededor de cinco millones de indios americanos vivían en lo que hoy se conoce como EE UU. A comienzos del siglo XIX, todavía quedaba alrededor de medio millón, pero en el año 1891 - fecha de la masacre de Wounded Knee — la población nativa había caído hasta un cuarto de millón, o sea un 5 por ciento del número original de indios. Confrontado con estos y otros datos similares, Darwin arguyó que determinadas razas humanas están condenadas a ser exterminadas. El filósofo liberal Herbert Spencer aclaró aún más la situación al afirmar que el imperialismo ha servido a la civilización al eliminar a las razas inferiores de la tierra (Lindqvist, 1998: 114-115 y 8).

En el siglo XIX en los Estados Unidos, la emergencia de un nuevo poder imperial estuvo acompañada de un discurso visible y claramente racista donde para ilustrar este asunto había dos variantes, que continuaron en el siglo XX y después. En primer lugar, se identifica el discurso beligerante expresado, por ejemplo, por Theodore Roosevelt, quien en la época de la guerra colonial en las Filipinas aseveró 
que el conflicto "significó el triunfo de la civilización sobre las fuerzas que apoyan el caos negro de lo salvaje y el barbarismo" y, continuó, "durante siglos la lucha que ha expandido los límites de la civilización en detrimento de la barbarie y el salvajismo ha representado uno de los factores más poderosos en el progreso de la humanidad" (citado en Kramer, 2006: 169).

Por otra parte, se puede encontrar la segunda variante en los escritos del Presidente Woodrow Wilson, quien en el mismo año que Theodore Roosevelt, es decir, 1902, escribió que "debemos gobernar [...] Y ellos deben obedecer como los que están bajo tutela" y, además, "en estas cuestiones de gobierno y justicia ellos son niños y nosotros hombres" (Wilson, 1902: 13). Esta segunda variante expresa una actitud condescendiente y etnocéntrica que está profundamente arraigada en los Estados Unidos y, de forma más general, en la sociedad occidental, y que ha afectado y continúa ejerciendo influencia en el devenir de las relaciones EE UU - Tercer Mundo. Se trata de un componente constitutivo del discurso imperial con un fuerte sesgo etnocéntrico del que Schoultz (1999), por ejemplo, nos ofrece múltiples ejemplos relevantes sobre su continuidad en la historia de los encuentros entre Estados Unidos y América Latina.

Una vez que hemos subrayado algunas de las cuestiones concernientes al vínculo o, mejor dicho, que entrelazan las ideas de imperialidad y racialidad, resulta apropiado añadir unos comentarios sobre las conexiones entre la imperialidad, la racialidad y la sexualidad. En el caso del imperio, puede decirse que fue visualizado en términos de "familia" en la que tanto mujeres como las razas inferiores pasaron a formar parte de un orden natural controlado por hombres blancos benevolentes y de clases acomodadas tanto dentro como fuera del país (Rattansi, 2007: 46). Rattansi continúa sugiriendo que se produjo una feminización del nativo en la colonia de tal forma que, por ejemplo, se pusieron nombres femeninos a las tierras colonizadas — siendo Virginia uno de los ejemplos más notables de esta tendencia-.

Es posible establecer una relación entre la observación de Rattansi y los trabajos sobre feminismo y poder imperial que estudian la situación presente. Por ejemplo, Schueller (2007), en su análisis sobre la dominación tecnológica y el imperialismo estadounidense, subraya la idea de que alrededor de la discusión sobre la naturaleza de la campaña Shock and Awe12, hay una invocación clara a la destrucción viril e hipermasculina basada en la destreza tecnológica. En este sentido, se crean categorías dentro de una lógica opresiva de construcción del género que nos retrotrae a la era colonial. Para Schueller (2007: 168), en el discurso imperial, se retrata continuamente al adversario como afeminado y despojado de su sexualidad. A través del

\footnotetext{
${ }^{12}$ [Nota de la T.] Shock and Awe, "Conmoción y Pavor" o Doctrina del Dominio Rápido, es un tipo de doctrina militar desarrollada por Estados Unidos que se basa en el despliegue de un poder y conocimiento del terreno de tal magnitud que anularía la voluntad del enemigo para luchar.
} 
fenómeno de la dominación tecnológica, se representa a la nación en términos viriles y con referencias al cuerpo masculino, mientras que al adversario se le dibuja como castrado y vulnerable.

Al considerar las escandalosas fotografías de las torturas en la prisión de Abu Ghraib, Schueller subraya la especial importancia de tres rasgos: a) el orgullo evidente demostrado por los soldados estadounidenses que posan en las fotos; b) la vulnerabilidad de los cuerpos de los prisioneros y, c) el contenido homosexual de muchas de las fotos. Para Schueller "todos estos rasgos ilustran la brutal dominación tecnosexual que caracteriza al imperialismo del EE UU contemporáneo" (Schueller, 2007: 175). Asimismo, añade que la sexualidad es el tropo más común de la dominación imperial y que "el poder fálico define al imperialismo". En Iraq, "la confluencia de prácticas de dominación imperial y los mecanismos de género del Orientalismo crearon las condiciones para la tortura sexual a través de la humillación y la otredad" (Schueller, 2007: 177). Aunque debe ser subrayado que el imperialismo no se refiere tan solo al género y la sexualidad, ésta sigue siendo una forma importante de control imperial.

En relación con la sexualidad, merece la pena señalar que en su trabajo sobre "conocimiento carnal y poder imperial", Stoler, 2010: xxiv) sugiere que los regímenes de seguridad imperial son capaces de anticipar lo que necesita ser controlado internamente - por ejemplo, el conocimiento profundo acerca de las amistades de la gente y sus vidas anteriores - y, en la misma medida, se aprecia una tendencia del sector militar estadounidense hacia la conversión de lo íntimo en un terreno estratégico. Así, por ejemplo, de acuerdo con Gregory, identificamos "la intimidad intrusiva de los sistemas biométricos usados por el ejército de EE UU con el fin de individualizar a la población iraquí" (Gregory, citado en Stoler, 2010: xxv).

Evidentemente hay mucho más que decir acerca de estos temas, pero mi propósito aquí ha sido el de simplemente señalar lo significativo de las conexiones entre lo imperial, lo racial y lo sexual, puesto que tal y como se puede comprobar, el imperialismo debe ser analizado en toda su complejidad cultural y, en particular, a través de sus componentes raciales, sexuales y políticos13. Además, resulta útil resaltar la idea de que el concepto de un nexo imperial nos obliga a buscar las interconexiones y solapamientos, de forma que, además de los vínculos entre imperialidad, racialidad y sexualidad, el presente imperial también se caracteriza por la imbricación de

\footnotetext{
${ }^{13}$ Se podrían referenciar muchas citas de Said, pero la siguiente parece especialmente pertinente: "No existe ninguna manera que yo conozca de aprehender el mundo desde dentro de la cultura americana [...] sin al mismo tiempo aprehender la propia disputa imperial. Esto, yo diría, es un hecho cultural de una importancia política e interpretativa extraordinaria, a pesar de que todavía no ha sido reconocido como tal en la teoría cultural o literaria, y resulta ser recurrentemente eludido u ocultado en los discursos culturales" (Said, 1993: 66).
} 
lo doméstico y lo internacional, así como del centro y la periferia —una cuestión que trataremos brevemente a continuación-.

Fue Foucault (2003) quien, al volver a examinar las relaciones centro-periferia, Occidente-resto del mundo en el siglo XVI, llamó nuestra atención sobre un "efecto boomerang" en el sentido de que mientras que la colonización, con sus técnicas y herramientas políticas, exportó los modelos europeos a otros continentes, también tuvo un efecto boomerang considerable sobre los mecanismos de poder en Occidente: "El resultado fue que Occidente pudo practicar algo parecido a la colonización o un colonialismo interno de sí mismo" (Foucault, 2003: 103).

Conforme nos aproximamos al final del siglo XIX y principios del siglo XX, encontramos el ejemplo del campo de concentración, que fue introducido por primera vez en Cuba por los españoles; hacia finales de 1897 el General Valeriano Weyler había enviado un número aproximado de 300.000 cubanos a los campos, en lo que España llamó una política de "reconcentración" de la población cubana en un periodo de insurgencia y guerra. Los británicos siguieron con este ejemplo en la guerra de los Bóer en Sudáfrica al encarcelar a miles de granjeros afrikáner. Cuarenta años más tarde los nazis intensificaron y generalizaron esta técnica abominable de poder coercitivo.

En su excelente relato sobre el control de la periferia imperial y el nacimiento del Estado de Seguridad Nacional, el historiador americano McCoy (2009) nos ofrece un ejemplo más duradero de una relación centro-periferia que, además, tiene lugar en las dos direcciones. Al comienzo del siglo XX, las fuerzas armadas estadounidenses capturaron Manila, una ciudad que había sido gobernada durante 350 años por España, y puede decirse que por primera vez en la historia los Estados Unidos se había convertido en un poder colonial e imperial. Sin embargo, en el caso de las Filipinas, que se convirtió en una colonia estadounidense desde principios del siglo XX hasta 1946, los Estados Unidos se encontraron con una insurgencia resistente que requirió ser pacificada durante aproximadamente quince años. Durante este tiempo la policía se convirtió en un instrumento clave del poder del Estado puesto que, liberado de los constreñimientos del sistema de justicia y la Constitución, el régimen colonial americano combinó nuevas tecnologías de la información e inteligencia militar para crear lo que McCoy, con razón, denomina el primer "Estado de vigilancia" del mundo (2009: 107). Para llegar a la consecución de este objetivo el ejército americano creó un complejo de fuerzas de seguridad (la renovada Policía Metropolitana de Manila, la Policía Paramilitar de Filipinas y su propia unidad de inteligencia de combate, la División de Información Militar) que empleó archivos de identificación fotográfica asociados a códigos numéricos y transferencia telegráfica de inteligencia bélica. Además, resulta significativo que en escasamente cinco años, el Cuerpo de Señales, compuesto de aproximadamente cuatrocientos hombres, hubiera instalado 5.355 millas de línea de teléfono fijo y 1.615 millas de cable submarino. 
McCoy observa asimismo que "a través de la penetración clandestina, la estrecha vigilancia y la inteligencia centralizada tanto en la capital como en las zonas rurales, la policía colonial estadounidense invadió el espacio social privado con el fin de recoger información incriminatoria acerca de la élite política del país" (2009: 110).

En general, puede decirse que los avances en las labores de policía de la periferia filipina del imperio fueron el reflejo de una expresión temprana del potencial represivo de las nuevas tecnologías de la información. Además, esta conquista colonial no solo convirtió a las Filipinas en un laboratorio social para el perfeccionamiento del poder del Estado estadounidense, sino que esta experiencia colonial también pasó a jugar un rol fundamental en la construcción del aparato de contrainteligencia en Washington y su incipiente capacidad de acción encubierta. Finalmente, puede decirse que los mandos experimentados de los Estados Unidos aplicaron las lecciones aprendidas en la represión de movimientos radicales filipinos para aplastar la revuelta de mineros militantes en los campos de carbón de Virginia Occidental — de acuerdo con McCoy (2009: 115), el único levantamiento armado contra el Estado americano en el siglo XX-.

\section{Reencuadramiento de la geopolítica de lo imperial: algunos comentarios finales}

En el libro que siguió a Imperio, es decir, Multitud, Hardt y Negri afirman que "la geopolítica imperial de hoy no tiene ni centro ni afuera; es una teoría de relaciones internas en el sistema global" (Hardt y Negri, 2004: 323). En su comentario a Hardt y Negri, Laclau arguye de forma eficaz que "la imagen de una totalidad imperial sin un centro $[. .$.$] del que los polos internos puedan haber desaparecido [. .$.$] no convence$ [...] lo único que tenemos que hacer es observar la escena internacional desde el 11S" (Laclau, 2005: 241). En el periodo que se abrió con el 11-S, los Estados Unidos han actuado como el centro de poder imperial y, tal y como observa Coronil (2007: 268), históricamente está claro que este país ha tenido una presencia imperial en América Latina. Lo que pretende el tipo de análisis acometido por Coronil es hacer la presencia imperial de los Estados Unidos a la vez más visible $y$ más intolerable.

$\mathrm{Al}$ comienzo de este artículo introdujimos la cuestión de la intervención y, más específicamente, de la intervención unilateral; y hemos vinculado este tema al impacto de la invasividad que, en nuestro análisis, se ejemplifica a través de los mecanismos del poder imperial. En respuesta a aquéllos que niegan la existencia del imperio, se puede argumentar que los Estados Unidos proyectan su poder militar globalmente, sus intereses económicos son globales, su alcance cultural es global y, 
en muchas formas, es un imperio más formidable de lo que ningún imperio haya sido jamás ${ }^{14}$. Lo que más extraña es que sus ciudadanos tienden a no reconocer este hecho, a pesar de que los Padres Fundadores abiertamente llamaban imperio a los Estados Unidos; por ejemplo, Hamilton declaró que la nación era el embrión de un gran imperio (citado en Hunt, 1987: 25) y Jefferson habló de un Imperio de la Libertad. Como nos recuerda Coronil, ciertamente es bastante poco realista tratar de entender la historia y la geopolítica de América Latina sin tener en cuenta los efectos de la proyección del poder de Estados Unidos. Sobre esta cuestión el historiador argentino Salvatore (2005: 26-27) llama la atención acerca de la variedad de protestas populares en contra de las intervenciones estadounidenses (por ejemplo, en Colombia y Bolivia con respecto a la "guerra contra las drogas", la imposición de políticas monetaristas en Argentina, Brasil y Venezuela y la ocupación territorial en Puerto Rico y Cuba). Salvatore señala asimismo que es importante analizar los cambios en el tipo de protesta antiimperialista, así como ser conscientes de las diferencias entre países en torno a la memoria de las intervenciones imperiales. Además, podemos mencionar también las distintas demostraciones de poder de Estados Unidos en América Latina; los distintos tipos de intervención, por ejemplo, en los años 1950 en Bolivia y Guatemala (Slater, 2010).

Cuando se discute la geopolítica de lo imperial, es importante tener en cuenta factores de cambio, mutación y proceso. Más que hablar de las ruinas del imperio, debemos poner el énfasis en un proceso de derrumbamiento que continúa, como ilustran los efectos del Agente Naranja en Vietnam (ver Stoler y McGranahan, 2013: 1-35). Junto a la dinámica del cambio geopolítico, se debe resaltar el significado de los agentes o protagonistas de la intervención imperial. En lugar de acercarnos a lo imperial desde un punto de vista marxista tradicional donde se asume que las estructuras tienen agencia — que las estructuras hacen cosas-, parece que sería de más ayuda examinar las imaginaciones geopolíticas de los intelectuales que trabajan dentro de los aparatos del Estado, como los neocon cuya contribución es bastante diferente de las de los neoliberales. La guerra, un Estado fuerte y una defensa orgullosa de la supuesta superioridad moral de América han sido el sello distintivo de los primeros (ver George, 2008) (5. $^{15}$

\footnotetext{
${ }^{14}$ Con respecto al poder militar y por lo que se refiere al gasto, en torno al año 2007 el gasto estadounidense en defensa rondaba el 45\% del total mundial, mientras que en 1986 correspondía al 28,2\% (Golub, 2010: 84). Por lo que se refiere a sus logros económicos, se puede decir que en torno al año 2010 la producción industrial de Estados Unidos suponía una quinta parte de la producción global; asimismo, de las 500 corporaciones más grandes del mundo, 132 tenían sede en EE UU, dos veces más que en ningún otro país. Ver Wikipedia, "The Economy of the United States", 2014.

${ }^{15}$ La principal diferencia entre los enfoques neoconservador y neoliberal está relacionada con que los neoliberales ponen un mayor énfasis en el mercado y el individualismo posesivo, mientras que, por el contrario, los neocon priorizan cuestiones de defensa, seguridad y cultura tradicional, y exhiben un mayor ímpetu de nacionalismo estadounidense.
} 
En definitiva, estamos ante un terreno profuso en temas y problemáticas y lo que he tratado de hacer en este artículo es abrir algunas vías y posibles puntos de entrada a la exploración, algo que potencialmente puede ayudar a renovar un campo de estudio importante.

\section{Bibliografía}

Anderson, Perry (2013) "American Foreign Policy and its Thinkers". New Left Review, núm. 83, número especial, 3-167.

Arendt, Hannah (1975) The Origins of Totalitarianism. Nueva York: A Harvest/HBJ Book [ed. original en alemán, 1951].

Atwood, Paul L. (2010) War and Empire. The American Way of Life. Londres y Nueva York: Pluto Press.

Barber, Benjamin R. (2004) Fear's Empire, war, terrorism and democracy. Nueva York y Londres: W.W. Norton \& Company.

Barnett, Thomas (2004) The Pentagon's New Map. Nueva York: Berkeley Books. Beitz, Charles R. (1979) Political Theory and International Relations. Princeton: Princeton University Press.

Berlan, J. P. (1952) "Introduction", en J. de Castro: The Geopolitics of Hunger. Nueva York: Monthly Review Press.

Beverley, John (2011) Latinamericanism After 9/11. Durham y Londres: Duke University Press.

Brzezinski, Zbgniew (2004) The Choice: global domination and global leadership. Nueva York: Basic Books.

Butler, Judith (2010) Frames of War. Londres y Nueva York: Verso.

Chomsky, Noam y Vltchek, Andre (2013) On Western Terrorism: From Hiroshima to Drone Warfare. Londres: Pluto Press.

Corradi, J. E.; Fagen, P. W., y Garretón, M. A. (eds.) (1992) Fear of the Edge. Berkeley: University of California Press.

Coronil, Fernando (2007) "After Empire: Reflections on Imperialism from the Americas", en A. L. Stoler et al. (eds.) Imperial Formations. Santa Fe y Londres: School for Advanced Research Press, 241-271.

Dahbour, Omar (2007) "Hegemony and Rights: On the Liberal Justification for Empire", en A. Dawson y M. J. Schueller (ed.) Exceptional State. Contemporary US Culture and the New Imperialism. Durham y Londres: Duke University Press. Department of Defense (2008) National Defense Strategy, Washington D.C.

Eisenstein, Zillah R. (2007) Sexual Decoys: gender, race and war in imperial democracy. Londres: Zed Books.

Foucault, Michel (2003) Society Must Be Defended. Lectures at the Collège de France 1975-1976. Londres: Allen Lane - Penguin Press.

Gaddis, John L. (2005) The Cold War. Londres: Penguin Books. 
Gareau, Frederick H. (2004) State Terrorism and the United States. Atlanta: Clarity Press y Londres: Zed Books.

George, Susan (2008) Hijacking America. How the religious and secular right changed what Americans think. Cambridge: Polity Press.

Gill, Stephen (2012) "Towards a Radical Concept of Praxis: Imperial «common sense» versus the postmodern prince". Millenium, vol. 40, núm. 3, 505-524.

Gilroy, Paul (2005) Postcolonial Melancholia. Nueva York: Columbia University Press.

Giroux, Henry A. (2004) "War on terror: the militarising of public space and culture in the United States". Third Text, vol. 18, núm. 4, 211-221.

Golub, Phillip S. (2010) Power, Profit \& Prestige. A History of American Imperial Expansion. Londres: Pluto Press.

Guardiola-Rivera, Óscar (2010) What if Latin America Ruled the World? Londres: Bloomsbury.

Hardt, Michael, y Negri, Antonio (2004) Multitude. Londres: Penguin Books.

Holden, R. H., y Zolov, Eric (eds.) (2000) Latin America and the United States: a documentary history. Oxford: Oxford University Press.

Hunt, Michael H. (1987) Ideology and US Foreign Policy. New Haven y Londres: Yale University Press.

Jameson, Fredric (1992) The Geopolitical Aesthetic. Indiana: Indiana University Press.

Johnson, Chalmers (2004) The Sorrows of Empire. Londres: Verso Books.

Joxe, Alain (2002) Empire of Disorder. Nueva York: Semiotext.

Kaplan, Amy (2002) The Anarchy of Empire in the Making of US Culture. Cambridge (Mass.): Harvard University Press.

Kelly, General John F. (2013) "Declaración sobre la Postura [Posture Statement]" del Comandante del Cuerpo de la Marina de los Estados Unidos, Comando Sur de los Estados Unidos, ante el $113^{\circ}$ Congreso". Comité del Senado sobre las Fuerzas Armadas, 19 de marzo de 2013.

Kennedy, Liam (1996) "Alien Nation: White Male Paranoia and Imperial Culture in the United States". Journal of American Studies, vol. 30, núm 1, 87-100.

Kiernan, Victor G. (1974) Marxism and Imperialism. Londres: E. Arnold.

Kramer, Paul A. (2006) "Race-making and colonial violence in the US empire: the Philippine-American war as race war". Diplomatic History, vol. 30, núm. 2, 169210.

Laclau, Ernesto (2001) "Democracy and the Question of Power". Constellations, vol. 8, núm. 1, 3-14.

Laclau, Ernesto (2005) On Populist Reason. Londres y Nueva York: Verso Books.

Laclau, Ernesto, y Mouffe, Chantal (1985) Hegemony and the Socialist Strategy. Londres y Nueva York: Verso Books.

Lefort, Claude (1988) Democracy and Political Theory. Londres: Oxford University Press. 
Lindqvist, Sven (1998) Exterminate All the Brutes. Londres: Granta Books.

McCoy, Alfred W. (2009) "Policing the Imperial Periphery: Philippine Pacification and the Rise of the US National Security State", en A. W. McCoy y F. Scarano (eds.) Colonial Crucible. Empire in the making of the modern American state. Madison: The University of Wisconsin Press, 106-115.

McNamara, Robert S. (1995) In Retrospect. Nueva York: Vintage Books.

Mehta, Uday S. (1999) Liberalism and Empire. Chicago: the University of Chicago Press.

Mignolo, Walter D. (2005) "Colonialidad Global, Capitalismo y Hegemonía Epistémica", en R. Salvatore (comp.) Culturas Imperiales. Buenos Aires: Beatrice Viterbo, 55-88.

Milne, Seumas (2012) The Revenge of History. Londres y Nueva York: Verso Books.

Mouffe, Chantal (2000) The Democratic Paradox. Londres y Nueva York: Verso Books.

Parekh, B. (1997) "The West and its Others", en K. Ansell-Pearson, B. Parry y J. Squires (eds.) Cultural Readings of Imperialism: Edward Said and the gravity of history. Nueva York: St. Martins Press, 173-193.

Pitts, Jennifer (2005) A Turn to Empire. Princeton: Princeton University Press.

Rancière, Jacques (1995) On the Shores of Politics. Londres y Nueva York: Verso Books.

Rattansi, Ali (2007) Racism. A very short introduction. Oxford: Oxford University Press.

Sader, Emir (2011) The New Mole: paths of the American Left. Londres y Nueva York: Verso Books.

Said, Edward W. (1993) Culture and Imperialism. Londres: Chatto and Windus.

Said, Edward W. (2003) Orientalism, with a new preface. Londres: Penguin Books.

Salvatore, Ricardo (2005) "Introducción: Repensar el Imperialismo en la Era de la Globalización", en R. Salvatore (comp.) Culturas Imperiales. Buenos Aires: Beatriz Viterbo, 11-35.

Scahill, Jeremy (2013) Dirty Wars, the world is a battlefield. Londres: Profile Books.

Schueller, Malini J. (2007) "Techno-Dominance and Torture Gate: the Making of US Imperialism", en A. Dawson y M. J. Schueller (eds.) Exceptional State: contemporary US Culture and the New Imperialism. Durham y Londres: Duke University Press, 162-188.

Schoultz, Lars (1999) Beneath the United States. Cambridge (Mass.) y Londres: Harvard University Press.

Sen, Amartya (2009) "Pip was right: nothing is so finely felt as injustice. And there the search begins". The Guardian, 13 de Julio, p. 26 [Puesto en línea el 13 de Julio de 2009. URL: 
http://www.theguardian.com/commentisfree/2009/jul/13/philosophy-justiceenlightenment-social-contract>, consultado el 14 de Julio de 2009].

Shane, Scott (2013) "US Torture Detainees after 9/11". International Herald Tribune, 16 de Abril, pp. 1 y 5.

Simpson, Brad (2012) "Bernath Lecture: The United States and the Curious History of Self-Determination". Diplomatic History, vol. 36, núm. 4, 675-694.

Singer, Peter W. (2012) “Do Drones Undermine Democracy?”. New York Times, 21 de Enero [URL: http://www.nytimes.com/2012/01/22/opinion/sunday/dodrones-undermine-democracy.html?pagewanted=all, consultado el 13 de Septiembre de 2013].

Slater, David (2010) "Rethinking the Imperial Difference: towards an understanding of US-Latin American encounters". Third World Quarterly, vol. 31, núm. 2, 185-206.

Stoler, Ann L. (2006) “On Degrees of Imperial Sovereignty”. Public Culture, vol. 18 , núm. 1, 125-146.

Stoler, Ann L. (2010) Carnal Knowledge and Imperial Power: Race and the Intimate in Colonial Rule. Oakland: University of California Press.

Stoler, Ann L., y MacGranahan, Carole (2013) "The Introductions: Refiguring Imperial Terrains", en A. L. Stoler y C. MacGranahan (eds.) Imperial Formations. Santa Fe: School for Advanced Research Press y Londres: James Curry, $3-42$.

The White House (2010) National Security Strategy of the United States. Washington DC.

Whyte, David (2007) "The Crimes of Neoliberal Rule in Occupied Iraq". British Journal of Criminology, vol. 47, núm. 2,177-195.

Williams, William A. (1972) The Tragedy of American Diplomacy. Nueva York: WW Norton \& Company.

Wilson, Woodrow (1902) "The Ideals of America". Atlantic Quarterly, December, p. 13.

Zinn, Howard (1996) The People's History of the United States. Nueva York: Longman. 